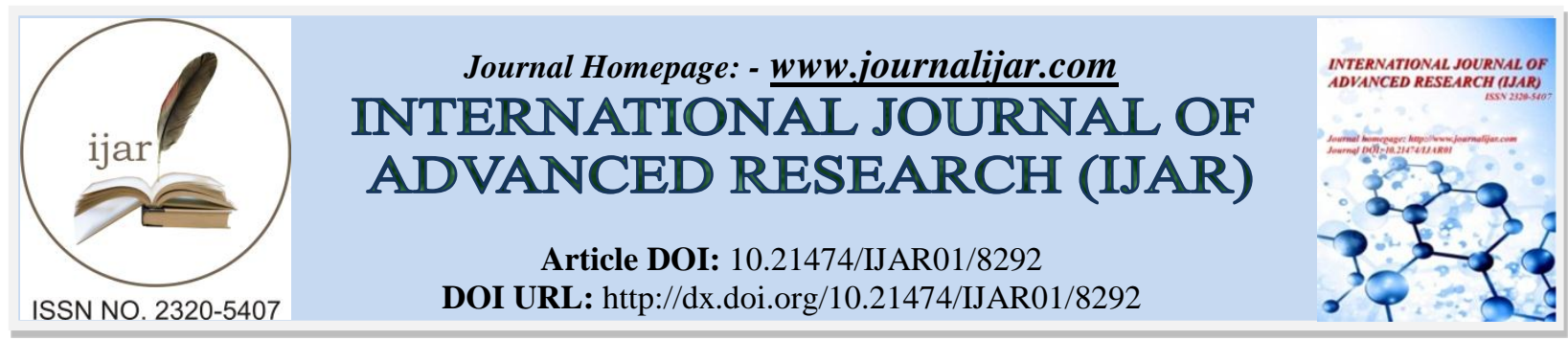

RESEARCH ARTICLE

\title{
A COMPLEMENTATION OF THE LABADA TEACHING MODEL FOR A GENDER SENSITIZED SOCIETY.
}

Cecille Estrelloso, ${ }^{1}$ Angelica Cuyno, ${ }^{2}$ Jaicha Gimoros, ${ }^{2}$ and Reynaldo B. Inocian ${ }^{2}$.

1. State Scholars, College of Teacher Education, Cebu Normal University, Cebu City, Philippines, 6000.

2. Institute for Research in Innovative Instructional Delivery (IRIID), Cebu Normal University, Cebu City, Philippines, 6000 .

\section{Manuscript Info}

\section{Manuscript History}

Received: 01 November 2018

Final Accepted: 03 December 2018

Published: January 2019

Keywords:

Sugbuanon countrywomen, images, gender role, gender sensitivity, labada.

\begin{abstract}
This study unveiled the images and worldviews of the Sugbuanon countrywomen and their expectations for a gender sensitive society by describing their images; their global perspectives; their expectations for a gender sensitive society; their success stories; and developing a gender sensitized teaching model that can be used in the instructional process. A descriptive qualitative method was used with Focus Group Discussions (FGD's). The data were recorded and transcribed, and were analyzed using narrative and thematic analyses. Bracketing was used to separate personal biases on key informants' narratives. Ethics protocol was observed to protect the confidentiality and anonymity of the key informants. The countrywomen's images, worldviews, expectations and success stories confirmed the convention of the society's social approval and norms. Twelve themes from key informants' narratives hinged Sandra Bem's Gender-typing Theory. The LABADA teaching model was crafted as a reminder of the cultural role of women in the society. Women in the 21 st century started to transcend to a more gender sensitized society, with respect to the equality of rights and equitability of resources.
\end{abstract}

Copy Right, IJAR, 2018,. All rights reserved.

\section{Introduction:-}

Since time immemorial, men have ruled the world; women have remained their subordinates. Women's voices are silenced, their faces are veiled and their capability is underestimated. The idea of men being powerful and highstatus roles corrupted the Philippine society. Men are expected to act strongly and be masculine. Women are expected to bow down to men and satisfy them. Women cannot be a sexual being the way men do. And so, men grow up masking their fragile side; women grow up in pretense silence. Society's expectation dictates the role of men and women. Gender expectations fail to recognize the true color, the uniqueness, and the happiness of female individuals. Socialization exaggerates the difference between men and women. Tracing its roots during the prehistoric times, the "datu," [village chieftain], was the ruler of the barangay. His wives were made objects to fulfill his needs and pleasure; likewise, the wives of his people. Women were full time housewives and mother to their children.

Corresponding Author:-Reynaldo B. Inocian.

Address:-Institute For Research In Innovative Instructional Delivery (IRIID), Cebu Normal University. 
When industrialization eventually arrived, people's lives have improved. Men have started to work in factories and departed from being a farmer or tenants of those wealthy families. In the urban setting today, women are hired in business and secretarial functions but receive less pay. On the other hand, in the rural and tribal setting, Filipino women are attached in the home. Countrywomen are known to be the "light of the home," manage the household. They serve as the treasurer of the family and budget the money given by their husband for their basic needs. They also serve as the counselor of the family; morally and economically support their children. Men are known to be the "head of the family" portray as the breadwinner. For non-family member [neighbors or friends] who need support, the wives are the best person to approach with.

In this modernizing society, the traditional role of women slowly vanishes and portrays a decisive role in the family. Various changes in rules, policies, and culture in our social environment are evident. Women's empowerment arises. The government implements a Magna Carta for Women to prevent gender oppression. It emphasizes nondiscrimination and provides equal privileges, opportunities and equal status for both sexes. It shifts society's perception and leads women to realize their roles and rights in the political, social, cultural and economic aspects. They are as important as men do. Women start to participate in the labor force and decision-making processes, acquire significant roles in the society and triumphantly venture in the field of medicine, engineering, and law which men formerly dominated.

Erlinda Ocifer, Floredelyn Patigayon and Mary Claire Abarquez are some of the illustrious women in Cebu who manage to stand in the business world which men rule. Gwendolyn Garcia and Agnes Magpale are two of the wellknown women politicians in Cebu who co-equal men in political leadership. Current research proves that diversity in gender helps businesses perform better. However, this notion is not widely accepted; gender biases still exist. Many are hesitant in the inclusion of women's talents, skills, and energies in the business, political or cultural world. Many still require women applicants to undergo intentional complex actions and deliberate policies. As gender sensitivity evolves, the traditional expectation of society towards gender role remains visible in rural areas. Hence, this study is conducted.

The result of this study is used to share the views of Sugbuanon countrywomen about issues on gender biases in relation to gender sensitive society and realize the significance of everybody's existence whether a man, a woman, a gay, a bisexual, and a transgender. To use women's success stories as a catalyst to inspire and motivate the youth and help the educational system in developing an appropriate curriculum that integrates gender equality in the teaching and learning process. Aiming for a progressive society, a curriculum [as a total learning experience of individuals] is not only used in schools; but it has an impact to the development of society. The establishment of the curriculum reflects dynamic changes in society. It includes written materials, which are collaboratively done by teachers and and other curriculum stakholders.

The result of this study is also relevant to the teachers that this study serves as basis in the selection of gender sensitized teaching strategies. With this gender sensitive approach in the curriculum, the abilities, skills, and talents of the learners become the center of the instructional process, which promotes gender equality and gender sensitive society.

\section{Objectives of the Study:-}

This study unveiled the images and worldviews of the Sugbuanon countrywomen and their expectations for a gender sensitive society by describing their images; their global perspectives; their expectations for a gender sensitive society; their success stories; and developing a gender sensitized teaching model that can be used in the instructional process.

\section{Review of Related Literature Images of Women}

Women feature different images, as they view the world differently and vary their expectations toward a gender sensitized society. Chimamanda Ngozi Adichie, during her TED talk entitled, "We Should All Be Feminist," emphasized that "men and women are two different individuals biologically and physically." She lamented that "women are different from men, so as men from women, that both possess skills and abilities that make them different from the other or sometimes, make women surpass men." Feminism in today's world is considered to be one of the hottest issues and latest trends. To Margaret Andersen in her sixth edition book, "Thinking about Women," social factors are the cause of both sexes' different position in the society. This becomes the central idea 
of feminism and its influence makes the women's involvement as the center of social changes. Feminists, all over the world, make different moves; but, they desire the same goal which builds a feministic society. Some women involve themselves in political movements from local to national. Although having different views and stance, the sole aim is equality. Women wanted to take part of men's occupied job opportunities and provide services to pursue their desired careers and to change family's tradition towards women (Allen, 1992). In traditional aspect, a patriarchal society put women under the rule of men. And it is also where women give up their demanding career in exchange to no pay, no benefit, no existing day-off and serve as women's lifetime career-being housewives. This system of patriarchy has always been part of a cultural context, which women reassert to eliminate in their advocacies.

\section{Gender Institutions}

A Chinese business magnate, the Alibaba Company's founder and executive chairman named Jack Ma mentioned in one of his interviews that environment's cosines and calmness are brought by female individuals. In today's century, women leaders are inevitable. Hence, Jack Ma's argument is observable in Cebu's three aspiring winners of "WINNERs" [Women In Need Now Entrepreneurs and Role models] namely: Erlinda Ocifer, Flordelyn Patigayon, and Mary Claire Abarquez sprung. Erlinda Ocifer, a resident of Tipolo Mandaue, starts a small business at her early age through selling packed goods like peanuts in Cebu City's Carbon Market. There, she has seen the life of being an ordinary vendor. Her parents instill her mind and the rest of her siblings the importance of having a business rather than attending to school and getting married afterwards. For her, making a business grow is not easy. Courage to face problems surpasses the challenges and commits to obtain success.

Flordelyn Patigayon, a resident in Canduman Mandaue, once belongs to a wealthy parent. Leaving her province to pursue high school in Cebu leads her to meet the man in her life. The agony starts when her parents no longer support her because of her relationship with a man his parents dislike because of having a low economic profile. Her passion for orchids is her stepping stone to become a successful entrepreneur. Mary Clair Abarquez, another resident of Canduman, starts out as a neophyte in the business career. For her, hard work, patience and faith become the secrets of her success. The stories of these three powerful women are proof of women's significant roles in society, which elevate their families' greatness and provide jobs to other families: they have contributed to local economy for sustainability.

Based on the study entitled "Women in the Workplace 2016," women were less likely to receive the first critical promotion to a manager. In every promotion between men and women, the former always have a greater possibility of being promoted than the latter. Influenced by literary works in which words had a positive denotations relating to male power, leadership and influence; women carried negative suggestions of weakness, inferiority and immaturity (Hyde \& Epstein, 1976). Furthermore, women in media institutions also experience gender discrimination and unequal opportunity. Global study of 522 news media organizations revealed that men acquire $73 \%$ of the positions at the top in media management. Women were overpowered by men in Cebu mass media (Balleza and Reyes (2006). Christine Roso's report on "Women behind the News" showed 70\% of media practitioners in Cebu are men and $30 \%$ are women. Surveys showed a higher percentage of professional women journalists; but, they failed to pursue their career because most of them fled the profession to raise families (Duin and Reyes 2006). It means that women cannot do multi-tasking to the point that they have to choose between career and motherhood. It is uncertain for the woman to have a good career in her chosen profession especially if she engages in married life. Management's perception that women's productivity decreased when they took on familial roles remained an obstacle to women's advancement within the media (Balleza \& Reyes, 2006). This is the reason that those who pursue their career in media choose to be single; in order not to be left out in the industry. The question of competence is another discrimination of a woman in media. They are perceived as weak; thus, deploying them to difficult situations like calamities is rare unlike men. Women in the media workforce are heard to be the newscaster in a television or a commentator in a radio program.

On the other hand, in a political perception, many say that women cannot lead a nation or a country for they are irrational and tend to keep changing their minds every now and then. A nation led by a female is considered weak. Yet, Ellis (2018) squelched, "The is no plausible evidence proving the irrationality of women than men and the rationality of both male and female comes equally." In fact, in the revised edition of "A History of the World" reveals that during 1558 in England, Elizabeth I [daughter of the Tudor ruler Henry VIII] was one of the great monarchs in Europe's history solidified the Church of England during her reign (Perry, 1989). The lady monarch managed to persuade the parliament to approve her policies. Likewise, in the Philippines, Corazon Conjuangco- 
Aquino in 1986 to 1992, the first female president managed to rule the entire country after the Marcos' 24 years of dictatorial regime; she successfully inculcated democracy during her reign.

\section{Gender-typing}

Gender-typing provokes gender role issue in the society. People are differentiated which results in inequality of rights and constraints in their personality, social life, and occupational path. As emphasized in the Social Cognitive Theory, differentiated gender originated in stereotypic qualities and roles, which were caused more on cultural rather than the biological aspect (Bussey \& Bandura, 1999). Gender stereotypes and roles are the outcomes of the internalization of people in the society. People's growth and development serve as one of the catalysts in the changes of the society that result in differentiated gender relationship foundation. In relation to this, gender schema theory described that concepts or ideas about the different aspect of humans' behaviors, personality, appearances and etcetera (Bem, 1981). It tends humans to have a gender-typed thinking and filters out information that contradicts stereotyping. Moreover, in theoretical perspectives; psychologically-oriented theories stressed intrapsychic processes which controlled gender development (Bussey \& Bandura, 1999) in which these were based on the cognitive structure of gender concepts. On the other hand, sociological theories emphasized socio-structural factors of gender-role development and functioning (Bussey \& Bandura, 1999). These perspectives are behavioral that influence women's orientation. In biologically-oriented theories, the gender differences delineated during the reproduction process of both sexes reinforced the differentiation and development of gender roles (Bussey \& Bandura, 1999).

\section{Complementation Theories in the Innovation of the LABADA Teaching Model}

Humans learned behavior is mostly influenced by the environment. Psychology affords to provide a foundation for the teaching-learning process of humans; either it is a cognitive or a behavioral theory. Operant conditioning is a behavioral theory which focuses on the changing of behavior of an individual by the use of reinforcement or punishment. This theory explains the three identified responses or operant that affects human behavior: neutral operants, reinforcers and punishers. Neutral operants are stimuli which neither discourage nor encourage the repeated behavior of an individual. Reinforcers are stimuli that encourage the behavior of an individual being repeated; it can be positive or negative whereas punishers are stimuli that discourage or weaken the behavior of individual being repeated. In this theory, punishments are highlighted as an ineffective way of controlling behavior and claimed that reinforcements, positive and negative, are way more effective in changing one's behavior unceasingly (McLeod, 2015). However, Edward Tolman, an American behaviorist, finds stimulus-response unacceptable thus, argues that people are an active information processes and not passive learners as indicated in behaviorism. According to him, reinforcement is not necessary for a learning to take place because behavior for him is mainly cognitive. He believes that individuals go beyond than merely responding such stimuli. Learners aim for goals which are usually based on their beliefs, attitudes and values. He calls this theory as cognitive mapping which is an internal image of the features and landmarks of the external environment (McLeod, 2015). It is the process of recalling, acquiring, and decoding information relative to their place or environment.

In relation to this, cognitive theories presented an opposition on the external and mechanistic focus of behaviorism. Gestalt Theory presents an organizational law which existed in the make-up of the human mind and the manner of structuring perceptions. Grouping was the central idea of this theory (Hamilton, undated). It says that the experiences and the learners' discernment have something to do on how they learn. They tend to organize their thoughts base on their lived experiences and consciousness. It also shows how real life instructions become the best instruction to use for the learners because the human brain has the ability to make a map of the stimuli cause by these life experiences; also known as isomorphism (L.D., 2015). Moreover, Reductionism theory indicated that in order to fully understand a complex phenomenon such as human behavior one must reduce its components first from complex to simplest (McLeod, 2013). The Gestalt theory is a holistic approach of learning in which in perception, the whole is different from the sum of its part while reductionism theory is a reductionist approach in which the simple is the source of the complex.

In behavioral theory, learners go beyond than merely responding to such stimuli while cognitive theories, learners organized their thoughts and ideas either in holistic approach or reductionist approach. All these concepts are significant on the learners' full growth and development and adaptation process thus; in this life stage phasesensitive learning occurs (New World Encyclopedia, 2018). This is also known as an imprinting psychology of Jean Piaget in which assimilation and accommodation of learning take place. Assimilation is dealing with new experiences with the use of existing knowledge in integrating it to the real life experiences while accommodation is 
the change or modification of existing knowledge that is not applicable in dealing and adapting to new experiences (Kendra, 2018).

\section{Research Methodology:- \\ Research Design}

This study utilized a qualitative-descriptive design. Unstructured questions were used in the Focus Group Discussions (FGD's) of key informants.

\section{Research Environment}

This study was conducted in the two far flung villages in Dumanjug, Cebu: Balaygtiki and Kanghumaod. These areas were suited in gathering significant data about the images of the Sugbuanon countrywomen. Hence, these villages were isolated in a mountainous location.

\section{Research Participants}

The research participants selected were suggested by the village chieftain in each of the two selected villages. These 30 informants or participants were categorized into three groups: ten wives, ten single women, and ten senior citizens.

\section{Research Instruments}

This study used a set of unstructured questions. This served as an interview guide for the key informants. These questions encompassed the identified variables of the study.

\section{Inclusion and Exclusion Criteria}

The key informants were chosen based on the following criteria: single women aged 15 to 20 years old, wives aged 30 to 50, and able senior citizens aged 60 and up. These key informants resided in the aforementioned locale of thes study. Men and members of the LGBT community were excluded in this study.

\section{Sampling Technique}

This study employed the convenience or availability sampling. In availability sampling each element in the population is selected based on convenience in the identified locale of the study. Key informants were conveniently approached when they went out of the house to clean the backyard, wash laundry, and resting in the house porch.

\section{Data Gathering Procedure}

Interview guide questions were examined and validated by the social science experts with background in Gender and Development studies. These questions were used in the FGD's. The data gathered in FGD's were transcribed, recorded and categorized in order to develop a gender sensitive curriculum design in teaching learning.

\section{Ethical Consideration}

Transmittal letters were given to the village chiefs for the approval of the FGD's. Letter of Informed Consent was signed by the key informants to prove that they were willing to give useful information of the study. After the final report was made, a cultural revalidation was conducted by presenting to the key informants for possible corrections. After the revision of the resport, transcripts were shredded to ensure ethical consideration.

\section{Data Analysis}

Data were analyzed using narrative and thematic analyses. The use of triangulation of data was also adopted. Theoretical sampling was used to revalidate the findings to the key informants before a final report was made for the publication of the paper.

\section{Results and Discussion:-}

\section{Theme 1: Image of Dependency}

"Dependency as a relational term has taken on pejorative connotation because of its long-standing identification as feminine characteristics" (Stiver, 208). Dependency on countrywomen is undeniable in rural areas, where they manage the home and take care of children and the elderly. They are regarded as an important figure of the management of resources and finances of the family. The management and distribution of resources and responsibilities ramify gender environment relations to daily life and people's well-being. Unaware of the 
developing world of the internet, they continue doing traditional living as a grandmother, a mother, and homemaker. Considered gender as God's preference and decision, they receive respect and learn to accept who they truly are and what gender has preferred on them. Based on the key informants' narratives, "Truly a woman because God willed for it." (KI-1) and "I am comfortable because the people and my husband respected me" (KI-1). Dependency to the church teaching and society's response to gender shape countrywomen's gender orientation. The way they live their lives is dependent on the influences of their families and the social environment. "In building our gender roles and creating our identity, the society played the big role" (Holt, 2018). As supported by the key informants, "The family nurtures us from childhood until we grow up." (KI-1) and "We take extra careful in our actions and the way we dress up to prevent ridicule" (KI-1). Pursuing education is no use because there is no degree that can change poverty. As what one of the key informants said, "No one gets rich in studying according to their parents" (KI-2). They believed that the end of women's journey is their fate to be attached at home (Rojas-Aleta, Silva, \& Eleazar, 1977). Women were found to be eleven times more likely to be associated with housework than were men (Holt, 2018). Women did not have the freedom to make decision in terms of purchasing and spending for they depended economically to their husband in the culture of patriarchy (Bhutta \& Haider, 2013). "Before, the couple stayed in the farm, they do not migrate." (KI-1) and "The husband is the sole breadwinner; but we help them in the farm activities" (KI-1). Still men superiority entails earning capabilities.

\section{Theme 2: Image of Domestication}

A mother and a wife was the common fate and mission of women that must be fulfilled (Zigaitis, 2018). The women had the greatest opportunity and ultimate goal to take care of their husband, their children and their home (Holt, 2018). As supported by the key informants, "The wife takes care of the children and does the household chores," (KI-3) and "we watch the children and discipline them" (KI-2). Sugbuanon countrywomen have a typical image to remain simple, conservative, and domesticated. They depicted to perform their domestic roles [cleaning, cooking, and child-rearing] and took care of their husbands (Hawn, 2018). Another domestic work that all women are into is the washing of the clothes called "labada." Labada is a Filipino word for laundry-a responsibility done mostly by women regardless of their age. In rural areas, women socialize with other women at times when they are gathered in a place called "sapa" or river during a "labada" or the day of laundry. As the labada continues, new ideas views, suggestions, opinions, and their burdens in life are are shared. It has become a form of a social bond. Similar to removing of stains in clothes, these women can also remove their negative thoughts and become positive with high hopes in achieving their goal. This orientation is rooted on the influence of their parents as what the key informants stated, "Our mother was the one who raised and disciplined me" (KI-2). This showed a resemblance on how daughters were trained by their mothers to be housewives (Quisumbing, 2016). And largely from the social environment they belong, they mentioned, "What is customary for everybody, we follow because if we pretend to be sociable, we are being talked about" (KIs-4\&5). Disch (1997) rejoined these narratives to mirror the individual's sensibility to regulate his or her social identity. Their sensibility toward their social environment and their parents' teachings shape their identity the way they live their lives. Parents' teachings and expectations to social environment are handed down from one generation to another becomes the pattern that countrywomen have strictly followed.

Women's biological capability, existing careers, and society's expectation pressured women to decide whether to have children and focused on child rearing or pursued her desired career, or the combination of both (Zigaitis, 2018). The countrywomen do not hesitate to give up their careers and advanced studies, in order to continue their traditional domestic role. For they believe that women sole purpose is fixed in the home, do household chores, and take care of the children and the husband" (KI-3) and "women are different because they have to work; while men are presumed to be right" (KI-4). But lack of men's assistance to house tasks makes women consider their role as a burden. "Being women is a privilege to be given with all the chores in the house; the wife is not expected only to take care the home and the family but to take care also the farm and the rest of the farm animals" (KI-4). While men are gainers; women also help a hand as a co-equal. While men are away from their families; women do the larger task at household chores and discipline their children. This is supported by this narrative: "Men have an edge because they are the breadwinner; whereas, we as wives we are only helping to earn a little income to add the budget" (KI-3). They believe that no equality has existed between men and women in terms of work. Men have a higher income in the family. Leaning on the gender pattern mobility, men did great in holding privileges; while women had difficulty in gaining around once gained, they lost it easily (Reeves \& Venator, 2018).

\section{Theme 3: Image of Transition}

The new generation of countrywomen is exposed to the evolving and easy access of technologies. With the exposure of people on social media, younger women change their perspective; they shift from traditional way of thinking into 
a wider scope of liberal thinking. These young adults envision themselves to be working ladies in the future, "I don't agree that women are made to stay at home, we need to work abroad and travel" (KI-3). For them, women have the right to pursue a career because of their right to employment. Young adults preferred the combination of being a mother and a career person (Zigaitis, 2018). This is rejoined by this narrative, "Hiring a babysitter to take care of the kids when mothers decide to work like their husbands" (KI-2). There was a significant variation to woman's traditional role when they pursued a career (Quisumbing, 2016). They are empowered with a wider perspective.

Conservativeness still remains an important trait among the new generation of countrywomen. Wearing of skimpy shorts is only good at home and wearing of make-up only for certain events. But, fashion preference has been influenced by the family and largely on the society's expectation, as revealed on this narrative, "We can hardly choose on what clothes to wear to avoid issues" (KI-1) and "do not wear skimpy short but they have to wear appropriately" (KI-2). Short hair is not preferred, "Sporting for short hair is not nice to look at what is appropriate for a woman is to have a long hair" (KI-2) for they perceive that sporting a long hair is an indicator of a true woman. At the end what matters most for them is their character.

\section{Theme 4: Worldview on Religious Predestination}

Religion becomes the center of the countrywomen's life and has contributed a big influence to their worldview. To the key informants, "It is important because God is our refuge." By having religion, they can give back to God's patients, guidance and blessings. Like every other religious individual, they also attend masses every Sunday and special occasions, and offer prayers to God. They follow the Biblical teachings and remain a strong believer. "Wives should be subordinate to their husbands so that, even if some disobeyed the word, they won over without a word by their wives' conduct" (The New American Bible, 2006). "Likewise, husbands should live with their wives in understanding, showing honor to the weaker sex, since they were joint heirs of the gift of life, so that their prayers were not hindered" (The New American Bible, 2006). These are some verses in the bible that they abide which shows condition on the women status over men as far as history of patriarchy is concerned. From the moment they are born, they are expected to bow down to their partners' desire. The bible's pre-conceived notion makes women to be in "a weaker vessel" that husbands are commanded to assign "honor." Husbands are asked to be considerate to their wives, to treat them with respect and care. Men's superiority put women's humanity at the foot of everything.

In socialization, they associate to anyone despite their looks, attitudes and status they have. Social standards are not prescribed because it promotes discrimination and social tension based on this narrative, "There is no measurement in socialization except understanding and humility are required (KI-3)." Great understanding and acceptance are understood to avoid chaos. Moreover, women have nothing to contribute to the country's economy because they are chained in doing domestic work. As narrated, "Before, the woman was attached to the farm; then and now, she still does the household chores as a homemaker (KI-5)." Women are tasked to manage the house and its environment; restricted to indulge in other responsibilities to get work and earn income. Likewise, gender oppression is evident in political aspect. "A woman is not allowed to participate in politics because mostly they are not respected and the community would be disorganized" (KI-4). When they enter politics, they are not recognized and respected; because they are stereotyped of being weak and fragile.

\section{Theme 5: Concepts of Gender Role Segregation}

Gender divides people into two equal-sized groups; between the disadvantaged and the advantaged group. Women's social world was affiliated in small organized groups: social and religious; while men were connected to a larger scope of work oriented groups (Ridgeway \& Smith-Lovin, 1999). This provides that women have an unequal access to opportunities which results in their low positional status. This supports this narrative, "Men are better to lead because they are stronger to lead and perform the expected responsibilities" (K1). "A woman shows a weak leadership" (K2), and "A woman is not meant for politics" (K3). It is obvious that less recognition and respect are given to a woman`s performance, capability, and rationality in political governance. This nuances a danger to the status of women in governance. Concept of women's inferiority is evident from their narratives. Males were recognized as stronger, collected, and well refined individuals, which, in turn, implied that the safety of one's country was dependent on the males' hand (Heinrich, 2005).

Likewise, on their economic perspective, women have nothing to do with the economy of the country because the duty of women is limited to the domestic activities such as: cleaning, cooking, gardening, babysitting their child, and taking care of their barnyard animals. As revealed on this narrative, "They have no contributions to the nations 
because their life is attached in the house (KI-2)." The males are working outside and making money because it is not appropriate for women to work for the family's sustainability. As revealed, "Women are not meant to work for the family (KI-2)." The women have roles in the household chores but not in the superior jobs like making business and others. This practice is passed on and imparted from generation to another. According to them, "We teach to our children what is right and customary in the community. We show what life is in the rural community so that their generation will not be surprised" (KI-4). By teaching these concepts, their descendants maintain the countrywomen's image to grow up with manners and learn to survive in the real world.

However, their real identity is uncertain from time to time. One factor that causes this is modernization. Though some experience a convenient life because of media technologies, it also brings a disadvantage in their community. As revealed, "Many families are destroyed because of a trending practice of infidelity. Our children are attached with their gadgets, which reduce communication and family bonding" (KI-5). Technologies disturb the good nature of the youth and destroy marital relationships. Their children tend to disobey them because of technology addiction and infidelity in marriage emerges because of more time and space distanciation. Discrimination of status is manifested and fake friendship becomes a trend. Though modernization reconstructs society, their religious nature remains the same. Each of them, as a family always attends a Sunday mass and utters prayers to the Lord, "Religion is important because this serves as guide in our life, there is no one who does not need the presence of God" (KI-1). Their everyday lives are guided by their religion and remained faithful to God. In fact, religion is a catalyst for relationship compatibility.

\section{Theme 6: Views on Social Approval}

Millennials have moved beyond the ideological battles of the counterculture of the 60's. They are now civic minded and reject the notion of patriarchal domination. They stand out on more liberal views on political and social issues living behind their familial practices and traditions. Millennials are ambitious enough in attaining leadership positions than their counterparts in developed markets. They do social transformation in which they adapt to the new emerging technologies and new ways of thinking and behaving. Thus, society's changes in business, governance, jurisdiction, and power were widely challenged (Arcinue \& Grata, 2016). Teenagers have adjusted to changes of modernization. They consider the importance of technology in their lives to conform the nurturance of the family. As argued, "We listen to our parents; but we also adopt the changes of society" (KI-7). On the other hand, KI-8 laments that "The young generations face their cellphones... sluggish to move and resist their parents." Teenagers' addiction towards technology affects negatively to their work phase and tends to disobey their mother. They develop their social standards in terms of attitude, fashion, and status in life, as revealed on this narrative, "We make friends to those with the same level with us" KI-6). They only make friends to those who meet their standards and make sure not to put themselves as inferior. They often find comfort in associating to people who have the same level as them.

They find the importance of education, as the only key in achieving success. When asked, "After finishing schooling; then we find a good job with better salaries in order to save." In order for them to proceed and survive, they must be educated. Education gives them a chance to be a productive citizen in the country and enables them to contribute in the economic progress. However, they also reveal that women have less participation in the progress of the economy because women tend to be a cave-dweller most of the time and tend to leave the responsibility at hand during marriage. As contested by their statement, "Most of the time, women most are domestically attached" (KI-8).

On the other hand, they recognize women's capability to lead in government. They believe that women have the right to be involved in politics because they are affectionate and capable in finding solutions to people's grievances. "Women should lead in the government because they can understand the feelings of everybody...can be easily approached, responsible, and full of ideas" (KI-7). However, one of them argues that men are more competent and credible in leadership aspect, "Men are better to lead because of their strength and aggressiveness...women are weak, moody, and have a changeable mind" (KI-8). They argue that women have greater emotional reactivity than men. Women were controlled by their intense emotion which defected their capability and aptitude of reason (The Myth of Female Part 1, 2016).

\section{Theme 7: Obedience to Social Norms}

Obedience to social norms is a manifestation that women live up to its expectations. "Before the one who raised us were strict that is why we manifested it" (KIS-2). They are being consistent with their images and worldviews. There is no reason for them not to follow the old ways because it is what they see in their parents and is still 
practiced at present. The characteristic of women's behavior is the expectation of the society. As KI-1 said "We take extra careful in our movements and behavior to prevent the criticism of the public." Moreover, success in education of their children and grandchildren is an achievement for them. "It is nice that children and grandchildren can finish schooling and earn a degree" (KIS-2). It gives them pride if they are able to finish their study and pursue a career. Likewise, hey have a negative perception regarding the LGBT community because they can never bear an offspring unlike straight women. Their location and less tolerance is one of the reasons why homosexuals rarely appear in their society. Heterosexuals are within the social norm based on the perceptions of the elderly key informants.

\section{Theme 8: Understanding Gender-typing}

In the countryside, the wives expect the same way singles do on gender-typing. "That is customary; it is impractical if you are from the countryside, you act like an urbanite" (KI-2). Contentment of their role suffices the wives' perception of being a housewife in the rural area. "Women are housewife so there is no need for them to have another position" (KI-1). As quoted in the book "Women and Work," "A housewife must possess values typical of being a home-maker; a word addressed defining married women who did not work for wages (Pineda-Ofreneo, 2005). Part of their being a housewife is the domestic work that she does not need to have another position. "Women have many tasks to do, they are just in the house" (KI-1).Women have so many household tasks. Women have jobs being paid in low amount as compared to men, who have a bigger part of unpaid tasks that rests on their care (Villaganas, Giango \& Basubas, 2016). They consider themselves as co-equal with men. "It is not true that there is inequality between men and women because both of their responsibilities are different" (KI-1). This rejoined that being a housewife is a co-equal to their husbands by dedicating herself to support her family to have a meal (Villaganas, et.al, 2016). Countrywomen accept the reality that they are co-equal with their husband in earning a living for their family. Wives' concept of inequality arises when pride, ego, and attitude take place. Each has to take someone's responsibilities to achieve equality.

Marriage disregards the importance of education in the part of the wives. "We stopped schooling when we got married so that we can discipline our children" (KIW-1). To Pineda-Ofreneo (2005), "Women's career amidst marriage life was set aside if these caused conflict to the needs of her husband and kids." A mother is worth the praise for giving the child a better education without thinking of her own good. It is considered as an achievement; they have not regretted it in their whole life. Acquisition of any professional degree drives every person to achieve because it is an invisible tool that lessens discrimination. "Even if we have not graduated for any degree, being a housemaker and a mother is a legacy that we have to leave to our children. With no job, we see to it that our children can finish a degree" (KIW-2). It carries a great impact than the career itself. Thus, inequality in education is evident because wives claim that the priority in education is given to men. "It is better that men can finish a degree because they can be a breadwinner in the family" (KI-2). Moreover, conformity to their sexual roles is necessary.

\section{Theme 9: Single Women's Narratives}

Women's expectations are set to what they are used in the society. They are bound to what is assigned and expected on them. "A woman exhibits to be feminine and a man exhibits to be masculine" (K1). They think on what everybody thinks as normal and acceptable. To Pineda-Ofreneo (2005), woman's work and man's work defined socially and culturally; depending on the needs of the institution. They perceive that it is necessary for them to live and respond to those expectations for the smooth flow of everything in society. Not doing so could lead to the negativity of their image and dignity. Despite that, they still consider themselves to be equal with men. "Men and women are equal; but men can take care of heavy works like fetching of water and gathering of firewood, which women can hardly make it" (KI-2). There is equality when each of them knows their responsibilities. Respect on each other constitutes equality "We have to be respectful all the time" (KI-1).

Likewise, education influences their expectations. There is a great persistence in achieving their goal to finish education. "Education is important for the future" (K2). Family strengthens their perseverance in pursuing the study. Family relationships would still be the number one priority (Pineda-Ofreneo, 2005). However, inequality is still evident because they have the willingness to give up their education or their career when this is needed for the family. Though there are many opportunities for women and men to prove their capability to a certain skill, still there are many constraints relating to gender that would prevent women to achieve on what they want (Pineda-Ofreneo, 2005). 


\section{Theme 10: Success Stories of a Good Wife}

Senior citizens are also vulnerable, independent, and indecisive. Women became vulnerable as compared to men in times of calamities due to their differences (Villaganas, et.al, 2016). What they prepare for their whole life is to become a responsible housewife, a mother and a good model to their grandchildren. "To stand up for being a wife" (KISC-1). In it, they encounter both pain and joy in life because of their dedication. "When one finds a worthy wife, her value is far beyond pearls," "Her husband, entrusting his heart to her has an unfailing prize" (The New American Bible, 2006). Proverbs describes the "capable wife" to have many qualities and talents which benefit their family because her husband trusted her. Moreover, Pineda-Ofreneo (2005) mentioned that for girls, work is an "adjunct to a relationship," their duties of being a future wife, a mother, a daughter or a sister. It is their challenge to nurture children well.

\section{Theme 11: Stories of Adversities}

Wives claimed their vulnerability; they were contented with their situation; and also they were vulnerable to other social pressures (Villaganas, et.al, 2016). They are independent and indecisive; they need to consult other people especially their husband for the validation and confirmation of their decision. "We cannot decide on our own because we are women" (KI-1). Being married is one of their greatest challenges. "It is not easy to be married because there are always challenges to encounter. No finances to spend for children's education, no work, no money. There are challenges to take care the kids" (KI-3). It entails great responsibilities in times of adversities.

KI-3 narrates her struggles and experiences as an OFW, "I went abroad in order to reach my ambition for my family's recovery, to send my siblings and future kids to school, to build a house; these are the reasons that I almost forget to marry." Forgetting one's own dream is a sacrifice. She continues further, "It is not easy to work abroad; what was said that we were made to work as a hospital attendant, when we arrived there we were made as domestic helpers. We were made to work all the household chores, even these were tedious; we survived. All kinds of pains came out because of too much work and not discounting the very hot weather condition of the place. We adjusted with the co-workers and the employment policies in Saudi Arabia." Flexibility is applied among all the situations experienced. Though, it is not an assurance that the persons who are the reason behind her struggles repay her, it proves on how she is dedicated to her family. She says further that, "It reached to the point that I regretted when nobody extended help in my dire need even if I knew they had something to give me." For 11 years of being an OFW, nothing has been saved for herself until she is married at the age of 36. All these adversities are encountered by the wives because of the culture of poverty. Ambition serves as a fuel that sustains to keep them going. The center for a mother's survival is her children.

\section{Theme 12: Stories of Ridicule}

Filipino culture continued to teach women gain reputation and respect about themselves (Majam, 2016). Women observe proper grooming to avoid discrimination in the society. "Women are ridiculed if they are stained during their monthly period" (KI-1). As a result of this stigma, slut-shaming becomes rampant and is considered as a social epidemic. As diversity continuously becomes more explicit, we have come to realize that people's capacities and talents vary. Skills, experiences and attitudes are different. But despite that, single women encountered challenges in which they feel that they doubt about their capacity to think. KI-2 mentions that, "They lack trust of the intelligence of a woman." Their achievement in academics is undermined; even if they claim that they are unique individuals, still people recognize each of their differences as unusual and the comparison is inevitable. Controlling to oneself is the ultimate destination. KI-2 said further "Women need self-regulation." After all, the family is never taken for granted in the list of their inspirations.

\section{Gender-Sensitized LABADA Teaching Model (LTM)}

To pay tribute to women in the countryside in their quest for a gender sensitized society, the LABADA Teaching Model or LTM is developed to improve teaching and learning process in the classroom. "Labada" is the Cebuano term for laundry or washing of clothes. This domestication shows how women strategically develop new ideas which in modern times are expressed in forums, counseling and assembly meetings. Tweaking the culture of labada to an instructional context becomes a reminder that labada is a gender-fair activity which everybody can now actively engage in, regardless of gender orientation. This offers a new perspective in eliminating a stigma of gender role segregation. In LTM, learners recognize labada, not just an ordinary house routine of washing clothes, but a new paradigm of a learning construct, that is dictated by a dialectical process of teaching. 


\begin{tabular}{|c|c|c|c|c|}
\hline $\begin{array}{l}\text { Required } \\
\text { Steps of the } \\
\text { LTM }\end{array}$ & Definition & $\begin{array}{l}\text { Instructional } \\
\text { Implications }\end{array}$ & $\begin{array}{c}\text { Learning Theories } \\
\text { Anchored }\end{array}$ & $\begin{array}{c}\text { Sample } \\
\text { Applications }\end{array}$ \\
\hline 1. Iway & $\begin{array}{l}\text { Iway means the } \\
\text { process of } \\
\text { separating the } \\
\text { colored clothes } \\
\text { from the white } \\
\text { ones }\end{array}$ & $\begin{array}{l}\text { Unlocking difficult } \\
\text { terminologies and } \\
\text { concepts. }\end{array}$ & $\begin{array}{l}\text { This applies B.F. Skinner`s } \\
\text { theory on operant } \\
\text { conditioning, which states that } \\
\text { controlling learners' behavior } \\
\text { can be done through } \\
\text { environment's stimuli: } \\
\text { reinforcers or punishers. }\end{array}$ & $\begin{array}{l}\text { Engagement } \\
\text { through the use of } \\
\text { conditioning } \\
\text { activities such as a } \\
\text { travelogue, brain- } \\
\text { teaser, etc., which } \\
\text { serves as primary } \\
\text { reinforcers }\end{array}$ \\
\hline 2. Humol & $\begin{array}{l}\text { Humol means } \\
\text { the process of } \\
\text { soaking clothes } \\
\text { with water mixed } \\
\text { with detergent in } \\
\text { a period of time }\end{array}$ & $\begin{array}{l}\text { Process of } \\
\text { contemplating the } \\
\text { concepts or lessons } \\
\text { taken. }\end{array}$ & $\begin{array}{l}\text { Gestalt theory of learning } \\
\text { explains that the whole is } \\
\text { greater than the sum of its } \\
\text { parts which means a unified } \\
\text { whole or a configuration of } \\
\text { ideas/patterns/pictures. } \\
\text { It also entails that learners best } \\
\text { learned through their first } \\
\text { hand experiences thus } \\
\text { immersion is necessary. }\end{array}$ & $\begin{array}{l}\text { Exploration by } \\
\text { actively } \\
\text { participating in } \\
\text { tiered activities that } \\
\text { enhance depth and } \\
\text { breadth of the } \\
\text { lesson. }\end{array}$ \\
\hline 3. Kuso-Kuso & $\begin{array}{l}\text { Kuso-kuso } \\
\text { means the } \\
\text { process of } \\
\text { removing the } \\
\text { dirt and stains of } \\
\text { the clothes } \\
\text { through hand } \\
\text { pressure }\end{array}$ & $\begin{array}{l}\text { The deepening } \\
\text { discussion proper of } \\
\text { the topic }\end{array}$ & $\begin{array}{l}\text { Tolman's Cognitive Map } \\
\text { Theory is a type of mental } \\
\text { representation that refers to the } \\
\text { individual's personal } \\
\text { knowledge or a schema which } \\
\text { allows an individual to } \\
\text { acquire, recall and decode } \\
\text { information. }\end{array}$ & $\begin{array}{l}\text { Explanation that } \\
\text { allows the learners } \\
\text { to interpret, to } \\
\text { analyze, and to } \\
\text { make implications } \\
\text { through the use of } \\
\text { problem-based } \\
\text { strategies. }\end{array}$ \\
\hline 4. Was-was & $\begin{array}{l}\text { Was-was means } \\
\text { the process of } \\
\text { rinsing the } \\
\text { clothes in a } \\
\text { running water }\end{array}$ & $\begin{array}{l}\text { The process of } \\
\text { extracting the } \\
\text { students' insights }\end{array}$ & $\begin{array}{l}\text { Reductionism theory practices } \\
\text { the manner of simplifying } \\
\text { complex } \\
\text { ideas/concepts/issues/conditio } \\
\text { ns to the point of minimizing } \\
\text { or distorting it in order to gain } \\
\text { its full understanding. }\end{array}$ & $\begin{array}{l}\text { Elaboration that } \\
\text { allows learners to } \\
\text { defend their } \\
\text { insights as they } \\
\text { apply them in a } \\
\text { contextualized } \\
\text { setting. }\end{array}$ \\
\hline 5. Hayhay & $\begin{array}{l}\text { Hayhay means } \\
\text { the process of } \\
\text { drying the } \\
\text { clothes by } \\
\text { hanging it on the } \\
\text { clotheslines } \\
\text { under the heat of } \\
\text { the sun }\end{array}$ & $\begin{array}{l}\text { The process of } \\
\text { enriching students' } \\
\text { learning in the real- } \\
\text { world situations }\end{array}$ & $\begin{array}{l}\text { Imprinting Psychology of Jean } \\
\text { Piaget is the assimilation and } \\
\text { accommodation of learning } \\
\text { wherein integration and } \\
\text { modification of knowledge are } \\
\text { applied to the new } \\
\text { experiences. }\end{array}$ & $\begin{array}{l}\text { Evaluation that } \\
\text { students document } \\
\text { their own learning } \\
\text { progress through } \\
\text { the use of different } \\
\text { means of } \\
\text { assessment. }\end{array}$ \\
\hline
\end{tabular}

\section{Conclusion:-}

The countrywomen's images, worldviews, expectations and success stories confirmed the convention of the society's social approval and norms. This validated the theory of Sandra Bem which stated that gender stereotypes and roles were the outcomes of the internalization or interaction of people in the society. However, women in the $21^{\text {st }}$ century started to transcend to a more gender sensitized society, with respect to the equality of rights and equitability of resources.

\section{Recommendation:-}

The study may recommend a massive education for all women in the rural areas in terms of gender sensitive concept; conduct training, seminars, programs and other gender sensitive awareness for the countrywomen in a 
concerted effort by the Local Government Units and the school institutions; and all educational institutions may use the LABADA teaching model as a reminder of the Sugbuanon countrywomen's flight to more gender sensitized communities in the Philippines.

\section{References:-}

1. Allen, R. (1992). Second Edition: Channels of Discourse, Reassembled Television and Contemporary Criticism. USA: The University of North Carolina Press.

2. Arcinue, P. A., \& Grata, A. (2016, August 11). Retrieved March 3, 2018, from http://scholar.google.com.ph

3. Balleza and Reyes, F. M. (2006). Women Media Practitioners in Cebu: The pioneers and Pacesetters. 11.

4. Bem, S. L. (1981). Gender Schema Theory: A Cognitive Account of Sex Typing. Retrieved from ahcafr.com: https://scholar.google.com.ph

5. Bhutta, R. N., \& Haider, J. (2013). Effects of Economic Dependecy on Decision Making Power of Women in Rural Areas of Tehsil Dera Ghazi Khan. International Journal of Academic Research in Business and Social Science.

6. Bussey, K., \& Bandura, A. (1999). Social Cognitive Theory of Gender Development - Semantic Scholar. Retrieved from researchgate.net: https://pdfs.semanticscholar.org

7. Disch, E. (1997). Reconstructing Gender A Multicultural Anthology Second Edition.

8. Duin and Reyes, F. N. (2006). Women Media Practitioners in Cebu: The Pioneers and Pacesetters. 10.

9. Ellis, A. (2018). Irrationality of Men and Women. Retrieved from iz Quotes: https://bit.ly/2AXLbKg

10. Hamilton, K. (n.d.). Google. Retrieved from Visual Communications: http://k3hamilton.com/vizcom/vizcom4.html

11. Hawn, A. (2018, 3 4). www.google.com. Retrieved from asu.edu: https://repository.asu.edu

12. Heinrich, J. (2005, May 5). Gender Role Within The Philippines. Retrieved from https://voivelab9.wordpress.com

13. Holt, J. (2018, 3 4). www.google.com. Retrieved from dev.csutan.edu: https://pdfs.semanticscholars.org

14. Hyde, J. S., \& Epstein. (1976). Understanding Human Sexuality. McGraw-Hill, Inc.

15. Kendra, C. (2018, May 24). Retrieved from Verywellmind: https://www.verywellmind.com/piagets-stages-ofcognitive-development-2795457

16. L, D. (2015, February 11). Retrieved from Learning Theories: https://www.learning-theories.com/gestalttheory-von-ehrenfels.html

17. Majam, Z. (2016, September). Today`s Carolinian, p. 22.

18. McLeod, S. (2013). Tolman-Latent Learning. Retrieved from Simply Psychology: www.simplypsychology.org/tolman.html

19. McLeod, S. (2015). Skinner-Operant Conditioning. Retrieved from Simply Psychology: www.simplypsychology.org/operant-contioning.html

20. New World Encyclopedia (2018, February 28). Retrieved from New World Encyclopedia: http://www.newworldencyclopedia.org/entry/Imprinting_(psychology)

21. Perry, M. (1989). A History of the World Revised Edition . Pines cor. Union Sts. Mandaluyong City: Cachos Hermanos, Inc.

22. Pineda-Ofreneo, R. S. (2005). Women and Work. Phillipines: University of the Philippines Open University.

23. Quisumbing, L. R. (2006). The River Flows On. Saranggola Publication Inc.

24. Reeves, R. V., \& Venator, J. (2018, 3 4). www.google.com. Retrieved from brookings.edu: https://goo.gl/t1gJhk

25. Ridgeway, C. L., \& Smith-Lovin, L. (1999). The Gender System and Interaction. Annual Reviews. Retrieved from http://www.jstor.org/stable/223503

26. Rojas-Aleta, I., Silva, T. L., \& Eleazar, C. P. (1977). A Profile of Filipino Women: Their Status and Role. Capitol Publishing House, Inc.

27. Stiver, I. P. (2018, 3 4). www.google.com. Retrieved from hhtps://wconline.org

28. The Myth of Female (Part 1). (2016, February 1). Retrieved from Illimitable Man: https://illimitablemen.com

29. The New American Bible (2006). 1 Peter 3:1, Saint Joseph Personal Size Edition.

30. The New American Bible (2006). 1 Peter 3:7, Saint Joseph Personal Size Edition.

31. The New American Bible (2006). Proverbs 31:10-11, Saint Joseph Personal Size Edition.

32. Villaganas, A. A., Giango, W. C., \& Basubas, E. O. (2016). A Life Dedicated to Support a Family Meal: The Women Trisikad Drivers`Story. European Scientific Journal, 121.

33. Zigaitis, K. M. (2018, 3 4). www.google.com. Retrieved from wustl.edu: https://openscholarship.wustl.edu. 